\title{
Nico M. van Gelder (1933-2005)
}

Nico Michel van Gelder died suddenly on September 19, 2005 , shortly after having completed "another day in the lab" in the Department of Chemistry, Queen's University. He was continuing to work on the design and development of novel amino acid analogues capable of penetrating diverse anatomical compartments within the human central nervous system.

Nico was born on Christmas Eve, 1933, in the highlands of Sumatra in the small village of Padang Sidempuan, Indonesia. He was the son of a high ranking Dutch civil servant and enjoyed an early childhood that was rich in books and intellectual curiosity. These intellectual adventures of youth abruptly ended in the late 1930s. The Japanese occupied the Dutch Indonesian colonies, and although just a child, Nico spent five years in a Japanese concentration camp. Following World War II and the subsequent independence of Indonesia, the van Gelder family returned to the Netherlands, but soon emigrated to Canada, settling in Montreal.

Once again able to pursue a formal education, Nico flourished. His first degree was a BSc in biology. He then attended graduate school under the supervision of Professor Kenneth Elliott, receiving a $\mathrm{PhD}$ in biochemistry in 1959 at the Montreal Neurological Institute. His PhD research provided some of the first landmark studies that eventually culminated in the recognition of GABA as an inhibitory amino acid neurotransmitter. Following his $\mathrm{PhD}$ studies, he completed his first postdoctoral fellowship at the prestigious Babraham Research Institute in Cambridge, England (1959-1960, under Professor J. H. Gaddum) and a second postdoctoral fellowship at the Harvard University Medical School (1960-1962, under Professor Stephen Kuffler).

In 1962, Dr. van Gelder became an assistant professor in the Department of Pharmacology at Tufts Medical School, Boston. During the next five years, Nico carried out a series of pioneering studies, providing the first description of GABAergic neuronal pathways, the first histochemical demonstration of GABA metabolism within the brain, and the first demonstration of a chemical blood-brain barrier for GABA.

In 1967, Nico returned to Canada having been recruited by Professor Herbert H. Jasper to join the Department of Physiology, Université de Montréal as an associate professor. He immediately participated in the creation of the Centre de Récherche en Sciences Neurologiques in Montreal and was a member of the Neurological Sciences Group, the first research group ever funded by the Medical Research Council of Canada. Nico was promoted to full professor in 1973 and remained in the
Department of Physiology until his retirement in 1997. During the 30 years from 1967-1997, he continued to demonstrate his mastery of amino acids, and showed a flair for medicinal chemistry when he developed analogues of aminooxyacetic acid and hydrazinopropionic acid as GABA aminotransferase inhibitors. He also developed analogues of taurine as putative anticonvulsant agents, and, together with Professor Anders Hamberger of Götebord, Sweden, devised and patented Amigran as a "metabolic treatment for migraine". During these years, he collaborated extensively with Professors Herbert Jasper, André Barbeau and Allan Sherwin.

In 1997, Nico telephoned me one day at Queen's University and said "Hi Don, I'd like a bench, make me some room". I was more than happy to do so. Over the subsequent years we enjoyed many conversations (arguments?) about the potential role of beta-alanine as a neuromodulator. At Queen's, he interacted with graduate students and medical residents, asking insightful questions in his uniquely kind, but crusty way. He continued to devise new molecular derivatives of taurine. In 2002, he even cheerfully took over the teaching of my Drug Design Medicinal Chemistry course at Queen's.

For over 40 years, Nico van Gelder has been an outstanding Canadian neuroscientist, publishing and patenting widely. He served on the editorial boards of many journals including Neurochemistry, Neurochemical Research, Neuroscience, Acta Neurologica, Journal of Neuroscience Research, Epilepsy Research and the International Journal of Developmental Research. In addition to these activities, he had an interest in promoting research in South America. He was actively involved in the training and funding of young scientists in Venezuela, ultimately being made a member of the Order of Andres Bello of Venezuela. Perhaps as a consequence of his own youth, Nico became committed to the study of starvation in children and its effects upon neuronal amino acid metabolism. This led to many international collaborations, particularly with research groups in Maracaibo and Caracas. At the time of his death, Nico was still an inquisitive neurochemist trying to improve amino acids and nutrition for the benefit of developing brains and developing countries.

Life is too short for some people, I think.

\author{
Donald F. Weaver \\ Canada Research Chair, Tier 1, Neuroscience, \\ Dalhousie University, Halifax, Canada.
}

